\title{
ASKING THE MENSTRUATION QUESTION TO ACHIEVE MENSTRUAL JUSTICE
}

\author{
MARGARET E. JOHNSON*
}

\begin{abstract}
Menstruation is a situs of discrimination, oppression, harassment, and microaggression. Employers fire workers for bleeding and experiencing period pain. Schools control menstruating students' access to bathrooms, products, and menstrual education. Prisons control their residents' free access to menstrual products. There are both "obvious and non-obvious relationships" between menstrual discrimination and discrimination on the basis of race, gender, class, gender identity, and disability. This Essay suggests we ask the "menstruation question" as part of our examination of all forms of intersectional oppressions and to achieve menstrual justice. ${ }^{2}$ For example, if we see something racist, we should ask "where is the menstrual oppression in this?" So too, if we see menstrual oppression, we should ask, "where is the racism in this?" Through this process, we discover the multidimensionality of menstrual injustices and how they operate as structural intersectionality. ${ }^{3}$ We learn that "dismantling any one form of subordination is impossible without dismantling every other." ${ }^{, 4}$ Therefore, asking the menstruation question is critical to achieve menstrual justice.
\end{abstract}

\footnotetext{
* Professor of Law, Co-Director, Center on Applied Feminism, Director, Bronfein Family Law Clinic, The University of Baltimore School of Law. Big thanks to my Symposium co-conveners Professor Bridget Crawford, Professor Emily Gold Waldman, Editor-in-Chief Sarah Ortlip-Sommers and Symposium Editor Jenna Lauter. And thanks to Professors Michele Gilman, Elizabeth Cooper and Marcy Karin for their helpful conversations about this Essay and work on menstrual justice.
}

${ }^{1}$ Mari J. Matsuda, Beside My Sister, Facing the Enemy: Legal Theory Out of Coalition, 43 StAn. L. Rev. 1183, 1189 (1991).

${ }^{2}$ This structure of inquiry follows the analysis of "ask[ing] the other question." Id.

${ }^{3}$ Kimberlé Crenshaw, Mapping the Margins: Intersectionality, Identity Politics, and Violence Against Women of Color, 43 StAn. L. Rev. 1241, 1265 (1991); Margaret E. Johnson, Menstrual Justice, 53 U.C. DAVIS L. REV. 1, 2, 71-76 (2019) (discussing how menstrual injustices are a form of structural intersectionality, "the overlapping forms of domination such as patriarchy, white supremacy, transphobia, classism, and ableism.").

${ }^{4} I d$. 


\section{INTRODUCTION}

Fifty years after its initial publication, Judy Blume's ARE YOU THERE GOD? IT'S ME, MARGARET remains a seminal novel exploring themes of personal identity-religious, familial, social, and cultural. The novel considers microaggressions and oppressions that create insiders and outsiders. Margaret's story is about puberty. And yes, it is (also) about menstruation. But while the book dramatizes cultural policing and oppression of other identities that occur simultaneously, the novel's notoriety is primarily the result of its depiction of cultural surveillance and control of menstruation - not religion, family, and social circles. This phenomenon underscores the need to acknowledge and address the interconnection of forms of discrimination. This Essay discusses a process of asking the "menstruation question," discussed below, as a path towards achieving menstrual justice, which seeks to identify, reduce, and remedy oppression of individuals who menstruate (menstruators), as well as other forms of oppression that may intersect with menstrual oppression.

Part I of this Essay discusses the concept of menstrual injustices and the goal of menstrual justice. Part II discusses the process of asking the menstruation question and how it helps to identify menstrual injustices, discover these injustices' connections to and intersections with other forms of injustice, and achieve menstrual justice as part of the overall project of dismantling oppression. Part III examines "asking the menstruation question" in a particular context-schools and the treatment of Black girls.

\section{Menstrual Justice}

The goal of menstrual justice is to identify, reduce, and remedy harm resulting from structural oppression of menstruators (menstrual injustices). It also aims to support menstruators' multidimensionality by working on inclusive, equitable, dignity-enhancing, and agency-enhancing reforms to law, policy, and praxis in collaboration with other social justice movements. ${ }^{5}$

There are several ways menstrual injustices manifest:

- Individuals who menstruate are essentialized as "feminine." Indeed, society only views cis girls and women as menstruators, thereby excluding transgender boys, transgender men, and individuals who are genderqueer/nonbinary or intersex. ${ }^{6}$

\footnotetext{
${ }^{5}$ See generally Johnson, supra note 3 (examining menstrual injustices in detail).

${ }^{6} I d$. at $26-28$.
} 
- Menstruators are discriminated against. For example, workers who menstruate face firing and disciplinary actions because they menstruate and leak blood unexpectedly in the workplace or suffer extreme period pain causing unforeseen absenteeism. ${ }^{7}$ Workers also are harassed about their menstruation. ${ }^{8}$

- Menstruators suffer insults and indignities. At school, for instance, teachers limit menstruating students' bathroom access or fail to provide them with biologicallyaccurate menstruation education. ${ }^{9}$

- Menstruators suffer economic disadvantages. Most notably, individuals who menstruate are required to pay a "tampon tax"10 and have limited access to affordable menstrual products which are not available for free in public buildings and cannot be purchased with food stamps. ${ }^{11}$

- Menstruators suffer health hardships that cannot be easily alleviated. Painful and disruptive disorders like endometriosis that negatively affect a menstruator's quality of life are underresearched and have limited treatment options. ${ }^{12}$

These menstrual injustices are intersectional. Indeed they are interconnected with the overlapping oppression stemming from "patriarchy, white supremacy, transphobia, classism, and ableism." 13 As an illustration, we may consider how low-income menstruators are more disadvantaged than other menstruators by the lack of publicly provided menstrual products and lack of food stamp coverage for them. ${ }^{14}$

${ }^{7}$ Id. at $28-45$.

${ }^{8} I d$.

${ }^{9}$ Id. at $45-53$.

${ }^{10}$ See generally Bridget J. Crawford \& Emily Gold Waldman, The Unconstitutional Tampon Tax, 53 U. Rich. L. REV. 439 (2019).

${ }^{11}$ Johnson, supra note 3, at 53-62.

${ }^{12} I d$. at $63-71$.

${ }^{13} I d$. at 2 (citing Crenshaw, supra note 3, at 1265). See also id. at 71-76.

${ }^{14} I d$. at 55 . For instance, one study showed that sixty-four percent of low-income menstruators could not afford tampons or pads to attend to their periods, evidencing their need for free products. Id. 
The goal of menstrual justice is to support the dignity, liberty, and equitable treatment of menstruators and eliminate structural intersectionality from menstrual injustices by:

- Eliminating discrimination and harassment.

- Ensuring that menstruators with limited financial resources have access to affordable and safe menstrual products of their choosing and sanitation facilities.

- Achieving ample funding for research on menstrual health and related pain and illnesses.

- Rigorously testing the safety of menstrual products.

- Normalizing menstruation as opposed to amplifying stigma and taboo; including and non-essentializing persons who are transgender, genderqueer/nonbinary or intersex; including and non-essentializing persons with disability.

- Creating a movement intertwined with other social justice movements such as the movements for racial justice, gender justice, disability justice, economic justice, health justice, reproductive health justice, housing justice, criminal justice and data justice. $^{15}$

A first step towards achieving menstrual justice is to ask the menstruation question.

\section{Asking the Menstruation Question}

Asking the menstruation question helps to examine all forms of relational or intersectional oppressions. This structure of inquiry follows the analysis of Mari Matsuda's asking the "other question."16 As Matsuda states:

When I see something that looks racist, I ask, "Where is the patriarchy in this?" When I see something that looks sexist, I ask, "Where is the heterosexism in this?" When I see something that looks homophobic, I

\footnotetext{
${ }^{15}$ For a discussion about the connection between data justice and menstrual justice movements see Michele Estrin Gilman, Periods for Profit and the Rise of Menstrual Surveillance, 41 COLUM. J. GENDER \& L. 100 (2021).

${ }^{16}$ Matsuda, supra note 1, at 1189.
} 
ask, "Where are the class interests in this?" Working in coalition forces us to look for both the obvious and non-obvious relationships of domination, helping us to realize that no form of subordination ever stands alone. ${ }^{17}$

Matsuda's line of inquiry allows us to reveal hidden or ignored forms of oppression and the interconnections between them. Applying Matsuda's formulation to menstrual injustices, we would ask the "menstruation question."

There are three ways in which asking the menstruation question operates to better serve inquiries and action promoting justice. First, similar to asking the other question, asking the menstruation question makes menstrual injustices seen when they would be otherwise invisible, helping to start the process of eradication. Second, asking the menstruation question unveils the connection of menstrual oppression to other forms of oppression so that all injustices may be identified and addressed. Third, because menstrual injustices often intersect - meanining they are coupled with and/or amplified by race, gender, class, gender identity, and disability injustices - asking the menstruation question reveals the structural intersectionality of menstrual injustices. As menstruators experience the compounding harms of menstrual injustices intersecting with other forms of injustice, asking the menstruation question helps us discover and recognize the "interconnection of all forms of subordination" 18 and invites diverse coalitions to address menstrual and other injustices.

\section{Asking the Menstruation Question to Achieve Menstrual Justice}

To demonstrate the menstrual justice goals of asking the menstruation question, this Part explores the inquiry by examining school-age menstruating students. The first section asks the menstruation question to identify menstrual oppression. The second section examines how when menstrual injustice is identified, the inquiry should continue to discover any other co-occurring form of oppression. The third section then reflects on the knowledge gained from asking the menstruation question: the discovery that menstrual injustices operate in multiple dimensions of oppression. Such structural intersectionality can result in different forms of harm that can only be disassembled by addressing all forms of oppression.

\footnotetext{
${ }^{17} \mathrm{Id}$.

${ }^{18} \mathrm{Id}$.
} 


\section{A. Asking the Menstruation Question to Identify Menstrual Oppression}

Asking the menstruation question forces the questioner to identify menstrual oppression where it was unseen in order to begin addressing it. For instance, much recent important scholarship has focused on how Black girls are subject to racial and gender inequality in school without exploring their subjugation to menstrual injustices. ${ }^{19}$

School officials often subject Black girls to inappropriate characterizations about their behavior in school and misunderstand their reactions to pervasive discrimination. ${ }^{20}$ One study found that adults consider Black girls and early teens "as less innocent and more adult-like than their white peers." ${ }^{21}$ Adults also view Black girls as needing less "nurturing, protection, and support." ${ }^{22}$ Consequently, these adults subject Black girls to harsher punishment and may overlook them for leadership development and mentoring opportunities. ${ }^{23}$

${ }^{19}$ See generally Rebecca Epstein, Jamilia J. Blake \& Thalia GonzÁlez, Girl Interrupted: The Erasure OF BLACK GIRLS' CHILDHOOD (2017), https://www.law.georgetown.edu/poverty-inequality-center/wpcontent/uploads/sites/14/2017/08/girlhood-interrupted.pdf [https://perma.cc/DK3F-JWJY]; NAACP LEGAL

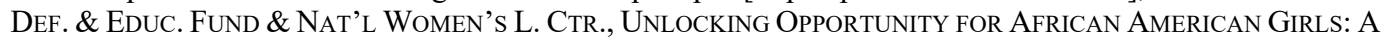
CALL to ACTION FOR EduCATIONAL EQUity (2014),

https://www.nwlc.org/sites/default/files/pdfs/unlocking_opportunity_for_african_american_girls_final.pdf [https://perma.cc/J7PP-SDUD]; Janie Boschma \& Ronald Brownstein, The Concentration of Poverty in American Schools, The AtLANTiC (Feb. 29, 2016),

https://www.theatlantic.com/education/archive/2016/02/concentration-poverty-american-schools/471414/ [https://perma.cc/GXG6-X7S2]. Interestingly, this important research and policy work around Black girls in school came from an ask the "other question" type process. Researchers studied the "school to prison pipeline" literature about the disproportionate punitive treatment of Black boys in schools leading to overincarceration and examined its fit for Black girls. See generally MONIQUE W. MoRRIS, RACE, GENDER

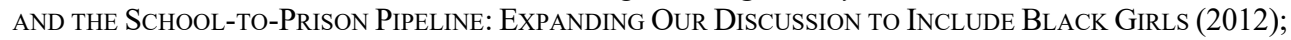
Kimberlé Williams Crenshaw, Priscilla Ocen \& Jyoti Nanda, Black Girls Matter: Pushed Out, OVERPOLICED AND UNDERPROTECTED (2015), https://www.atlanticphilanthropies.org/wpcontent/uploads/2015/09/BlackGirlsMatter_Report.pdf [https:/perma.cc/Q7WZ-HYZ9].

${ }^{20}$ Monique W. Morris, Pushout: The Criminalization of Black Girls in School 8-9 (2016) (explaining that "too many Black girls are being criminalized (and physically and mentally harmed) by beliefs, policies, and actions that degrade and marginalize both their learning and their humanity, leading to conditions that push them out of schools and render them vulnerable to even more harm.”).

${ }^{21}$ EPSTEIn, BlaKe \& GonZÁLEZ, supra note 19, at 1 (emphasis in original deleted).

${ }^{22} I d$.

${ }^{23} I d$. 
Dr. Monique Morris' research shows that there is a dynamic in schools where Black girls try to fight discrimination by speaking up for themselves and demanding treatment with dignity, only to be subject to harsher discipline than their white counterparts. ${ }^{24}$ Moreover, Black girls are often enrolled in "zero-tolerance schools . . . in which discipline is prioritized over educational attainment." ${ }^{25}$ Schools create a sense of insecurity for Black girls by failing to recognize their achievements or intervening in bullying or sexual harassment incidents. ${ }^{26}$ The totality of these disproportionate effects on Black girls leads them to be "pushed out of schools ... and other places where they might otherwise feel whole." ${ }^{27}$

The newfound and important focus on Black girls in school documents troubling unfair treatment by schools. But it misses an important area of inequity: these reports do not address treatment of the students around the issue of menstruation. Asking the menstruation question reveals that Black girls and girls of color also suffer negative treatment because of menstruation. Asking the menstruation question provides a more holistic view of the multidimensional and structural forces of oppression.

This dimension of injustice was unveiled recently by seven eighth grade girls of color in the Bronx Prep Middle School who created a podcast on periods that won the NPR Student Podcast Challenge. Their podcast asks the menstruation question and explores the hostile environment towards menstruators in their school and community. The podcast discusses period poverty (the inadequate access to menstrual products and bathroom facilities); the tampon tax (the higher cost of period products because they are subject to sales or value-added tax); school officials' perpetuation of shame and taboo about menstruation; and the lack of appropriate menstrual education for all students. ${ }^{28}$ Discussing school officials' shaming of young menstruators, the podcasters explain how students are steered away from openly discussing menstruation, directed to use coded

\footnotetext{
${ }^{24}$ MORRIS, supra note 20, at 8-9, 11-12, 19-20; see CRENSHAw, OCEN \& NANDA, supra note 19, at 9.

${ }^{25}$ CRENSHAW, OCEN \& NANDA, supra note 19, at 9.

${ }^{26} I d$. at 10.

${ }^{27}$ MORRIS, supra note 20, at 20.

${ }^{28}$ Sssh! Periods, Episode 01. Marshmallow, https://soundcloud.com/shehtaz-huq/sssh-periods [https://perma.cc/6TZ2-J24M]; Elissa Nadworthy \& Clare Lombardo, Periods! Why These 8th-Graders Aren't Afraid to Talk about Them, NAtional PuBlic Radio (May 15, 2019, 5:02 AM), https://www.npr.org/2019/05/15/721729850/periods-why-these-eighth-graders-arent-afraid-to-talk-aboutthem [https://perma.cc/PY5A-7N7X].
} 
language to hide menstruation, and ordered not to reveal that they are menstruating. ${ }^{29}$ As Caroline Abreu states, if they need a menstrual pad, they have to go to a special school office and ask for a "marshmallow." "30 And Kathleen Restitullo states that the school posted signs in bathroom stalls telling the students to not let anyone view their menstrual product. $^{31}$

In addition to shaming, school officials' regulation of menstruating students' bathroom access has been documented. Strict access is dictated by formal rules and teachers' informal policies. ${ }^{32}$ Compliance by rule-following menstruating students limits their ability to timely change their menstrual products and may result in blood leakage onto clothes and school furniture. ${ }^{33}$ It also risks the students' health as regular tampon substitution is critical to avoiding toxic shock syndrome. ${ }^{34}$ Former teachers rightly have called these policies " "dehumanizing." "35 As podcaster Abreu states, "I'm literally the queen of bleeding out. . . . It's not usually my fault; it's because I can't go to the bathroom during class." ",36

By asking the menstruation question, the podcasting students shine a light on a taboo subject and demand that their voices be heard to identify the discrimination and harm and seek menstrual justice. Openly discussing menstruation also let the podcasters use their voice to demand dignity from their school and their community. As their teacher Shehtaz Huq stated, "They're all intelligent, articulate women, and for once, they didn't have to

${ }^{29}$ Nadworthy \& Lombardo, supra note 28.

${ }^{30} I d$.

${ }^{31} I d$.

${ }^{32}$ Margaret E. Johnson, Emily Gold Waldman \& Bridget J. Crawford, Title IX and Menstruation, 43 HARV. J.L. \& GENDER 225, 241-43 (2020).

${ }^{33} I d$.

${ }^{34}$ What Happens During the Typical 28-Day Menstrual Cycle?, U.S. DeP'T OF HeAlth \& HuMAn SERVS., OFFICE ON WOMEN's HEALTH, https:/www.womenshealth.gov/menstrual-cycle/your-menstrual-cycle [https://perma.cc/8X9Z-PYU7].

${ }^{35}$ Johnson, Waldman \& Crawford, supra note 32, at 242 (internal citation omitted).

${ }^{36}$ Nadworthy \& Lombardo, supra note 28. 
dumb it down. They could just be authentic and fiercely intelligent and show the world what they are capable of . ..."37

This process of asking the menstruation question can be useful in other circumstances too. Where there are other forms of discrimination, asking the menstruation question can reveal and then help to address menstrual and other injustices.

\section{B. Asking the Menstruation Question to Identify Other Forms of Subordination}

The second benefit of asking the menstruation question is to surface and examine the interconnection between different forms of subordination, such as menstrual oppression and racism, for instance. Matsuda's structured inquiry requires the inquirer not to stop after spotting one form of injustice, but rather to keep asking questions to find other injustices. So too with asking the menstruation question. After identifying menstrual injustices, one should continue and ask: Where is the white supremacy in this? The partriarchy? The heterosexism? The transphobia? The classism? The ableism? And so on.

The Sssh!Period podcast by the Bronx Prep School girls of color also demonstrates this second advantage of asking the menstruation question by revealing other forms of oppression. After they gained national acclaim in examining the menstrual injustices in their school and community, they published twenty-one additional podcast episodes. In their episodes, the girls draw the connection between the "culture of shame" in menstrual oppression and other forms of oppression. For instance, the students connect the thread between menstrual oppression and the policing of young women and young women of color's bodies through dress codes. ${ }^{38}$ From there, the students cover such topics as the social "white washing" of desirable hair (namely straight and able to be dyed), policing of boys and men through gender stereotypes, birth control, homelessness, and more. ${ }^{39}$ Through their seamless exploration of these topics, the girls show that asking the menstruation question leads to other questions of connected oppression that need to be

\footnotetext{
${ }^{37}$ Democracy Prep Bronx Middle, Young Women from Bronx Prep Middle Win National Competition for their Podcast, "Sssh! Periods", The Democracy Prep Blog (Aug. 30, 2019), http://blog.democracyprep.org/young-women-from-bronx-prep-middle-win-national-competition-for-theirpodcast-sssh-periods/ [https://perma.cc/J4KE-6989].

${ }^{38} \mathrm{Sssh}$ ! Periods, Episode 02. Shoulder Straps, Hemlines and the ACLU, https://soundcloud.com/shehtazhuq/sssh-periods-episode-2 [https://perma.cc/3DTJ-Q262].

${ }^{39} \mathrm{Sssh}$ ! Periods, https://soundcloud.com/shehtaz-huq/sssh-periods [https://perma.cc/86GP-Z6TK] (see Episodes 20, 16, 8 and 19 respectively).
} 
explored within their school and community to achieve menstrual justice and other forms of social justice.

\section{Asking the Menstruation Question to Address Structural Intersectionality of Menstrual Injustices}

The third value of asking the menstruation question is that it reveals that menstrual injustices are not just situated proximately to other injustices, but also may be intersectional, causing a different form of oppression because of a person's membership in social categorizations of race, gender, and gender identity, for example. Yes, menstrual injustices often are based on gender subordination as they target menstruators who are cis women, cis girls, and others who have a uterus and an ovary, such as some transgender men and boys and individuals who are intersex and genderqueer/nonbinary. But how those menstrual injustices target and harm persons varies based on the intersectionality of their social categorizations and the discrimination at issue.

For instance, controlling school-age menstruating students' access to bathrooms negatively impacts all menstruators. Young menstruators at the intersection of gender and age are subject to structural disadvantages different from nonmenstruating students of the same age when schools restrict their bathroom access. Cisgender girls report the humiliation of their schools' limited bathroom access. ${ }^{40}$ They detail how restricted access results in their unnecessary menstrual staining from leaking, stigma, and absenteeism while menstruating. ${ }^{41}$ To access the restroom, they often have to disclose their menstruation status to receive teacher permission, something a young teen may be uncomfortable doing around peers. This menstrual injustice on its own most likely violates Title IX as Professors Bridget Crawford, Emily Waldman and I have argued elsewhere. ${ }^{42}$ It should be remedied by more liberal bathroom access.

Asking the menstruation question helps to uncover the structural intersection of bathroom access regulation and how it may impact Black cisgender girls and trans boys, for instance, in differing ways than white cisgender girls. Because the research shows that Black girls are overpoliced in school and subject to greater discipline for infractions, bathroom regulation of menstruators undoubtedly will harm more severely Black cisgender girl menstruators than their white counterparts. And transgender boys' requests

\footnotetext{
${ }^{40}$ Johnson, supra note 3 , at 74 .

${ }^{41} I d$.

42 Johnson, Waldman \& Crawford, supra note 32, at 244-250.
} 
to teachers to access the bathroom due to menstruation may involuntarily out them in front of their peers causing a different harm than to cisgender students who make similar requests. Accordingly, the school example shows that when menstrual injustices meet at the intersection of gender, race, age, and gender identity, the harms may be quite different than when they do not. And this understanding leads to additional changes that schools should enact to address the structural intersectionality of school menstrual injustices, such as not policing bathroom access infractions and trusting students' need to access the bathroom and not requiring a verbalized reason.

Accordingly, the process of asking the menstruation question reveals that "menstrual injustice is the operation of power through intersecting and multidimensional structures of oppression based on gender, gender identity, race, class, sexual orientation, disability, etc."43 Dismantling menstrual injustice requires identifying and dismantling all injustices.

\section{CONCLUSION}

To address menstrual injustices and other connected forms of oppression, we should ask the menstruation question. To do so, for example, if we see something racist, we should ask "where is the menstrual oppression in this?" So too, if we see menstrual oppression, we should ask, "where is the racism in this?" Asking the menstruation question is critical to achieving menstrual justice, which seeks to identify, reduce, and remedy harm from structural oppression of menstruators while supporting their multidimensionality, inclusion, dignity, liberty, and equitable treatment through law, policy, and practices in collaboration with other social justice movements. It also seeks to eradicate all other forms of patriarchy, white supremacy, classism, and ableism.

\footnotetext{
${ }^{43}$ Johnson, supra note 3 , at 76.
} 